\title{
Pengaruh Perencanaan, Pemberdayaan dan Pengembangan Sumber Daya Manusia Terhadap Kinerja Karyawan Divisi LIS II di PT. Maspion II Sidoarjo
}

\author{
* Khoirun Nisak, Asmie Poniwatie, Indah Noviandari \\ Program Studi Manajemen Fakultas Ekonomi dan Bisnis \\ Universitas Bhayangkara Surabaya, Indonesia
}

DOI: $10.46821 /$ ekobis.v1i2.27

\begin{abstract}
ABSTRAK
Perencanaan merupakan langkah awal perusahaan dalam menentukan arah dari perusahaan terutama dalam merencanakan sumber daya manusia. Selanjutnya, didukung oleh pemberdayaan manusia yang baik dan tepat. Namun hal tersebut perlu ditunjang dengan pembangangan sumber daya manusia yang baik agar kinerja karyawan semakin meningkat. Meski begitu, dalam pelaksanaanya masih seringkali terdapat hambatan. Tujuan dari penelitian ini adalah untuk mengetahui pengaruh perencanaan, pemberdayaan dan pengembangan sumber daya manusia terhadap kinerja karyawan Divisi Lis II di PT. Maspion II Sidoarjo. Penelitian ini menggunakan pendeketan kuantitatif dengan pengumpulan data menggunakan kuesioner. Populasi dari penelitian ini adalah seluruh karyawan PT. Maspion II Sidoarjo yang berjumlah 1220 orang dimana 92 orang dijadikan sampel dengan metode Probability Sampling. Metode analisis yang digunakan ialah dengan analisis regresi linear berganda dengan uji hipotes yaitu uji $\mathrm{F}$ dan uji t. Hasil dari penelitian ini menunjukan bahwa perencanaan, pemberdayaan dan pengembangan sumber daya manusia berpengaruh signifikan secara parsial maupun simultan terhadap kinerja karyawan.
\end{abstract}

Kata kunci : Perencanaan, Pemberdayaan dan Pengembangan Sumber Daya Manusia,Kinerja Karyawan

\begin{abstract}
Planning is the company's initial step in determining the direction of the main company in human resource planning. Furthermore, it's supported by good and proper human empowerment. But it's still needs to be supported by the development of good human resources in order to improve company performance. But, in the implementation there are still challenges. The purpose of this research is to study the planning, empowerment and development of human resources towards the development of employees of the LIS II Division at PT. Maspion II Sidoarjo. This study uses a quantitative short with data collection using a questionnaire. The population of this study is all employees of PT. Maspion II Sidoarjo which took 1220 people where 92 people were sampled by the Probability Sampling method. The analytical method used is multiple linear regression analysis with the hypothesis test that is the $\mathrm{F}$ test and $\mathrm{t}$ test. The results of this study indicate that planning, empowerment and development of human resources show the simultaneous significance of employee performance.
\end{abstract}

Keywords: Planning, Empowerment and Development of Human Resources, Employee Performance 


\section{PENDAHULUAN}

Globalisasi semakin membuat jarak dan waktu seolah sudah tidak lagi menjadi masalah bagi seseorang untuk menjangkau ilmu pengetahuan dan informasi darimanapun, kapanpun dan dimanapun.

Perencanaan Reily dalam Sutrisno (2016: 33) menyebutkan bahwa perencanaan sumber daya manusiaberkaitan erat dengan pengidentifikasian persoalan-persoalan, ancaman-ancaman, dan peluang-peluang dalam organisasi dan lingkungan organisasi.

PemberdayaanMenurut Sedarmayanti (2016: 310), pemberdayaan manusia adalah suatu usaha atau upaya untuk lebih memberdayakan "daya" yang dimiliki oleh manusia itu sendiri berupa kompetensi, wewenang, dan tanggung jawab dalam rangka meningkatkan kinerja organisasi.

Elmi (2018: 69) menjelaskan pengembangan sumber daya manusia (human resource development) adalah proses peningkatan kualitas atau kemampuan manusia. Hal tersebut dilakukan dalam rangka mencapai tujuan.

Kinerja menurut Whitmore dalam buku Dr. Ir H. Al Fadjar Ansory, MM \& Dr. Meithiana Indrasari, ST , M.M "Manajemen Sumber Daya Manusia" (2018), mengemukakan kinerja berasal dari kata kerja yang maksudnya adalah aktivitas yang dilakukan seseorang atau organisasi dalam menjalankan tugas yang menjadi pekerjaannya.

\section{TINJAUAN PUSTAKA}

\section{Perencanaan}

Sedarmayanti (2016: 131), menyebutkan bahwa perencanaan SDM adalah kegiatan untuk mengantisipasi permintaan atau kebutuhan dan suplai tenaga kerja organisasi di masa yang akan datang.

\section{Pemberdayaan}

Menurut Sedarmayanti (2016: 310), pemberdayaan manusia adalah suatu usaha atau upaya untuk lebih memberdayakan "daya" yang dimiliki oleh manusia itu sendiri berupa kompetensi, wewenang, dan tanggung jawab dalam rangka meningkatkan kinerja organisasi.

\section{Pengembangan}

Elmi (2018: 69) menjelaskan pengembangan sumber daya manusia (human resource development) adalah proses peningkatan kualitas atau kemampuan manusia.

\section{Kinerja}

Busro (2018:88), menyebutkankinerja adalah kesediaan seseorang atau kelompok orang untuk melakukan sesuatu kegiatan dan menyempurnakannya sesuai dengan tanggung jawab dengan hasil seperti yang diharapkan.

\section{METODE PENELITIAN}

\section{Populasi}

Sugiyono (2015:80) populasi adalah wilayah generalisasi yang terdiri atas obyek/subyek yang mempunyai kualitas dan karakteristik tertentu yang ditetapkan oleh peneliti untuk dipelajari dan kemudian ditarik kesimpulanya. Populasi juga bukan sekedar jumlah yang ada pada obyek/subyek yang dipelajari, tetapi meliputi seluruh karasteristik atau sifat yang dimiliki subyek atau obyek itu. 


\section{Sampel}

Sugiyono (2015 : 81) menyatakan bahwa sampel adalah bagian dari jumlah dan karakteristik yang dimiliki oleh populasi tersebut. Sampel ini diambil karena dalam penelitian ini tidak mungkin diteliti seluruh anggota populasi.

\section{Prosedur Pengumpulan Data}

Sugiyono (2015:225), bila dilihat dari sumber datanya, pengumpulan data dapat menggunakan sumber primer dan sumber skunder. Sumber primer atau data primer adalah data yang langsung memberikan data kepada pengumpul data, dan data sumber sekunder merupakan sumber yang tidak langsung memberikan data kepada pengumpul data, misalnya lewat orang lain atau lewat dokumen.

\section{Pengujian Data}

Uji Validitas, Pengujian validitas ini dilakukan untuk menguji data yang telah diperoleh sehingga dapat mengukur valid atau tidak nya suatu kuisioner. Uji reliabilitas digunakan untuk mengetahui apakah indikator atau kuesioner yang digunakan dapat dipercaya atau handal sebagai alat ukur variabel.

\section{Teknik Analisis Data dan Uji Hipotesis}
a. Analisis Regresi Linier Berganda
b. Analisis Koefisien Determinasi
c. Uji F dan Uji T
d. Pembuktian Dominan

\section{HASIL ANALISIS DAN PEMBAHASAN}

\section{Uji Validitas}

Berdasarkan hasil tabel diatas menunjukkan bahwa semua indikator memiliki $r$ hitung > r tabel yaitu sebesar 0,2050. Maka dapat disimpulkan bahwa semua pernyataan untuk variabel pengembangan sumber daya manusia adalah valid dapat dilanjutkan ke pengujian selanjutnya.

\section{Tabel 1}

\section{Uji Validitas Perencanaan}

\begin{tabular}{lcccc}
\hline Indikator & r hitung & Tanda & r tabel & Keterangan \\
\hline Pengadaan (X1.1) & 0,615 & $>$ & 0,1726 & Valid \\
Kompensasi (X1.2) & 0,769 & $>$ & 0,1726 & Valid \\
Kedisiplinan (X1.3) & 0,780 & $>$ & 0,1726 & Valid \\
Pemberhentian (X1.4) & 0,611 & $>$ & 0,1726 & Valid \\
\hline
\end{tabular}

Sumber: Data Diolah peneliti, 2020

\section{Tabel 2}

Uji Validitas Pemberdayaan Sumber Daya Manusia

\begin{tabular}{lcccc}
\hline Indikator & r hitung & Tanda & r tabel & Keterangan \\
\hline Otoritas (X2.1) & 0,770 & $>$ & 0,1726 & Valid \\
Akses Informasi (X2.2) & 0,658 & $>$ & 0,1726 & Valid \\
Dukungan organisasi (X2.3) & 0,586 & $>$ & 0,1726 & Valid \\
Penyedia sumber daya dan & 0,814 & $>$ & 0,1726 & Valid \\
informasi (X2.4) & & & &
\end{tabular}

Sumber: Data Diolah peneliti, 2020 


\section{Tabel 3}

\section{Uji Validitas Pengembangan Sumber Daya Manusia}

\begin{tabular}{lcccc}
\hline Indikator & r hitung & Tanda & r tabel & Keterangan \\
\hline Pendidikan dan pelatihan (X3.1) & 0,680 & $>$ & 0,1726 & Valid \\
Kegiatan non-diklat (X3.2) & 0,680 & $>$ & 0,1726 & Valid \\
Promosi Jabatan (X3.3) & 0,780 & $>$ & 0,1726 & Valid \\
Motivasi kerja (X3.4) & 0,625 & $>$ & 0,1726 & Valid \\
\hline
\end{tabular}

Sumber: Data Diolah peneliti, 2020

Tabel Uji 4

Validitas Kinerja Karyawan

\begin{tabular}{lcccc}
\hline Indikator & r hitung & Tanda & r tabel & Keterangan \\
\hline Kualitas pekerjaan (Y1.1) & 0,673 & $>$ & 0,1726 & Valid \\
Kuantitas kerja (Y1.2) & 0,731 & $>$ & 0,1726 & Valid \\
Waktu (Y1.3) & 0,648 & $>$ & 0,1726 & Valid \\
Pengawasan (Y1.4) & 0,595 & $>$ & 0,1726 & Valid \\
Hubungan antar karyawan (Y1.5) & 0,446 & $>$ & 0,1726 & Valid \\
\hline
\end{tabular}

Sumber: Data Diolah peneliti (2020)

\section{Tabel 5}

Hasil Perhitungan Uji Reliabilitas

\begin{tabular}{llllll}
\hline & \multicolumn{1}{c}{ Variabel } & $\begin{array}{c}\text { Cronbach's } \\
\text { Alpha }\end{array}$ & Tanda & $\begin{array}{c}\text { Minimal } \\
\text { Cronbach's } \\
\text { Alpha yang } \\
\text { Disyaratkan }\end{array}$ & Keterangan \\
\hline 1 & $\begin{array}{l}\text { Perencanaan (X1) } \\
\text { Pemberdayaan }\end{array}$ & 0,645 & $>$ & 0,60 & Reliabel \\
2 & $\begin{array}{l}\text { Sumber Daya } \\
\text { Manusia (X2) }\end{array}$ & 0,670 & $>$ & 0,60 & Reliabel \\
& $\begin{array}{l}\text { Pengembangan } \\
\text { Sumber Daya } \\
\text { Manusia (X3) }\end{array}$ & 0,622 & $>$ & 0,60 & Reliabel \\
4 & $\begin{array}{l}\text { Kinerja Karyawan } \\
\text { (Y) }\end{array}$ & 0,603 & $>$ & 0,60 & Reliabel \\
\hline Sum
\end{tabular}

Sumber: Data Diolah peneliti, 2020

\begin{tabular}{|c|c|c|c|c|c|c|}
\hline \multicolumn{7}{|c|}{$\begin{array}{c}\text { Tabel } 6 \text { Uji F } \\
\text { ANOVA }^{\mathbf{a}}\end{array}$} \\
\hline Model & & Sum of Squares & $\mathrm{df}$ & Mean Square & $\mathrm{F}$ & Sig. \\
\hline \multirow[t]{3}{*}{1} & Regression & 8.054 & 3 & 2.685 & 33.708 & $.000^{\mathrm{a}}$ \\
\hline & Residual & 7.008 & 88 & .080 & & \\
\hline & Total & 15.062 & 91 & & & \\
\hline
\end{tabular}

Sumber: Data Diolah Peneliti (2020) 


\begin{tabular}{|c|c|c|c|c|c|}
\hline & $\begin{array}{r}\text { Tab } \\
\text { Uji } \\
\text { Coeffic } \\
\end{array}$ & $\begin{array}{l}\text { el } 7 \\
\text { T } \\
\text { cients }^{a} \\
\end{array}$ & & & \\
\hline Model & $\begin{array}{r}\text { Unsta } \\
\text { Coe }\end{array}$ & $\begin{array}{l}\text { ndardized } \\
\text { fficients }\end{array}$ & $\begin{array}{l}\text { Standardized } \\
\text { Coefficients }\end{array}$ & $\mathrm{t}$ & Sig. \\
\hline & $\mathrm{B}$ & Std. Error & Beta & & \\
\hline (Constant) & .707 & .316 & & 2.233 & .028 \\
\hline Perencanaan $(\mathrm{X} 1)$ & .255 & .075 & .297 & 3.417 & .001 \\
\hline Pemberdayaan SDM (X2) & .278 & .088 & .283 & 3.162 & .002 \\
\hline Pengembangan SDM (X3) & .303 & .078 & .330 & 3.870 & .000 \\
\hline
\end{tabular}

a. Dependent Variable: Kinerja karyawan (Y)

Sumber: Data Diolah Peneliti, 2020

\section{Uji F}

Hasil pengujian model secara bersama-sama (simultan) di atas diperoleh nilai $F_{\text {hitung }}$ sebesar 33,708. Nilai ini lebih besar daripada Ftabel sebesar 2,15. Demikian juga dengan nilai signifikan yang dihasilkan sebesar 0,000 yang jauh lebih kecil dari nilai signifikan (Tabel 6).

\section{Uji T}

Dari hasil perhitungan variabel perencanaan dapat disimpulkan mengenai uji $\mathrm{t}$ (parsial) ditunjukkan dengan hasil perhitungan $t$ hitung yang menunjukkan nilai 3,417 . Sedangkan dengan rumus $t$ tabel $(\alpha / 2 ; n-k-1)$ yaitu $(0,05 ; 88)$ diperoleh $t$ tabel sebesar 1,66235yang berarti $t$ hitung $>\mathrm{t}$ tabel.Dari hasil perhitungan variabelpemberdayaan sumber daya manusia dapat disimpulkan mengenai uji $t$ (parsial) ditunjukkan dengan hasil perhitungan t hitung yang menunjukkan nilai 3,162 . Sedangkan dengan rumus $t$ tabel $(\alpha / 2 ; n-k-1)$ yaitu $(0,05 ; 88)$ diperoleh $t$ tabel sebesar 1,66235yang berarti $\mathrm{t}$ hitung $>\mathrm{t}$ tabel.Dari hasil perhitungan variabelpengembangan sumber daya manusia dapat disimpulkan mengenai uji $t$ (parsial) ditunjukkan dengan hasil perhitungan t hitung yang menunjukkan nilai 3,870 . Sedangkan dengan rumus $t$ tabel $(\alpha / 2 ; n-k-1)$ yaitu $(0,05 ; 88)$ diperoleh $t$ tabel sebesar 1,66235yang berarti t hitung > t table (Tabel 7).

\section{Uji Dominan}

Dari Tabel 8, menunjukan variabel perencanaan memiliki koefisien beta sebesar 0,297 atau 29,7\%. Variabel pemberdayaan sumber daya manusia memiliki koefisien beta sebesar 0,283 atau 28,3\% dan variabel pengembangan sumber daya manusia memiliki koefisien beta sebesar 0,330 atau 33\%. Ini menunjukan bahwa variabel pengembangan sumber daya manusia memiliki koefisien beta terbesar diantara variabel bebas lainnya yang berarti bahwa variabel pengembangan sumber daya manusia merupakan variabel yang dominan berpengaruh terhadap kinerja karyawan. 


\begin{tabular}{|c|c|c|c|c|c|c|}
\hline \multicolumn{7}{|c|}{$\begin{array}{c}\text { Tabel 8 } \\
\begin{array}{c}\text { Melihat Pengaruh Dominan } \\
\text { Coefficients }^{\mathrm{a}}\end{array}\end{array}$} \\
\hline & & \multicolumn{2}{|c|}{$\begin{array}{l}\text { Unstandardized } \\
\text { Coefficients }\end{array}$} & \multirow{2}{*}{$\begin{array}{c}\begin{array}{l}\text { Standardized } \\
\text { Coefficients }\end{array} \\
\text { Beta }\end{array}$} & \multirow[b]{2}{*}{$\mathrm{t}$} & \multirow[b]{2}{*}{ Sig. } \\
\hline & & $\mathrm{B}$ & Std. Error & & & \\
\hline \multirow{4}{*}{1} & (Constant) & .707 & .316 & & 2.233 & .028 \\
\hline & Perencanaan (X1) & .255 & .075 & .297 & 3.417 & .001 \\
\hline & $\begin{array}{l}\text { Pemberdayaan } \\
\text { SDM (X2) }\end{array}$ & .278 & .088 & .283 & 3.162 & .002 \\
\hline & $\begin{array}{l}\text { Pengembangan } \\
\text { SDM (X3) }\end{array}$ & .303 & .078 & .330 & 3.870 & .000 \\
\hline
\end{tabular}

a. Dependent Variable: Kinerja karyawan (Y)

Sumber: Data Diolah Peneliti, 2020

\section{SIMPULAN}

Hasil analisis uji $\mathrm{F}$ diperoleh nilai $\mathrm{F}$ hitung sebesar 33,708 dengan signifikansi sebesar 0,000. Oleh karena itu F hitung $(33,708)>F$ tabel $(2,15)$ dan nilai signifikansi yang dihasilkan sebesar 0,000. Hasil analisis uji $t$ variabel Perencanaan (X1) diperoleh nilai t hitung 3,417 dengan tingkat signifikansi sebesar 0,001.Dari tiga variabel bebas yang terdiri dari Perencanaan (X1), Pemberdayaan Sumber Daya Manusia (X2) dan Pengembangan Sumber Daya Manusia (X3) dapat diketahui bahwa variabel Pengembangan Sumber Daya Manusia (X3) mempunyai nilai koefisien $\beta$ (beta) terbesar 0,33 yang merupakan nilai terbesar diantara variabel-variabel bebas yang lain. Dari hasil penelitian diketahui bahwa variabel Perencanaan, Pemberdayaan Sumber Daya Manusia dan Pengembangan Sumber Daya Manusia berpengaruh simultan (bersama-sama) dan signifikan terhadap variabel Kinerja Karyawan Devis Lis II PT. Dari hasil penelitian bahwa variabel Perencanaan, Pemberdayaan Sumber Daya Manusia dan Pengembangan Sumber Daya Manusia berpengaruh parsial (sendiri-sendiri) dan signifikan terhadap variabel terikat Kinerja Karyawan Devis Lis II PT. Bagi peneliti selanjutnya, hendaknya untuk mengembangkan penelitian ini dengan menggunkaan variabel atau indikator yang berbeda sehingga diperoleh informasi yang lebih lengkap tentang faktor-faktor yang mempengaruhi kinerja karyawan.

\section{DAFTAR PUSTAKA}

Ajeng Tria Jayanti Wulandari dan Widiartanto. 2019. Pengaruh Pemberdayaan Karyawan, Self Efficacy dan Kompensasi Terhadap Kinerja Karyawan(Studi Pada Karyawan Produksi CV Jordan Semarang). E-Journal Universitas Diponegoro.

Ajmal As'ad. 2018. Pengaruh Perencanaan Kerja dan Komunikasi Terhadap Kinerja Karyawan. Jurnal Ilmu Ekonomi Vol.1 No.1. 
Arikunto, Suharsimi. 2014. Prosedur Penelitian: Suatu Pendekatan Praktik. Jakarta: Rieneka Cipta.

Busro, Muhammad. 2018. Teori-Teori Manajemen Sumber Daya Manusia. Jakarta : PRENADAMEDIA GROUP.

Dadan Ahmad Fadili, Rd. Dwi Yulianti S, Aji Tuhagana dan Asep Jamaludin. 2018. Pengaruh Pelatihan Kerja Dan Pengembangan SDM Terhadap Kinerja Karyawan. Jurnal Buana Ilmu Vol.3 No.1

Desseler, Gary. 2015. Manajemen Sumber Daya Manusia. Jakarta: Salemba Empat.

Elmi, Farida. 2018. Telisik Manajemen Sumber Daya Manusia. Jakarta: Mitra Wacana Media

Faida, Eka Wilda. 2019. Manajemen Sumber Daya Manusia dan Ergonomi Unit Kerja Rekam Medis. Sidoarjo: Indomedia Pustaka

Ghozali, Imam. 2016. “Aplikasi Analisis Multivariate Dengan Program IBM SPSS 23". Universitas Diponegoro. Semarang.

I Putu Magna Anuraga, Desak Ketut Sintaasih dan I Gede Riana. 2017. Pengaruh Kepemimpinan Dan Pemberdayaan Terhadap Motivasi Dan Kinerja Pegawai. E-Jurnal Ekonomi dan Bisnis Universitas Udayana Vol.6 No.9

Kasmir. 2016. Manajemen Sumber Daya Manusia (teori dan praktik). Jakarta: Rajagrafindo Persada.

Panjaitan, Maludin. 2017. Pengaruh Pengembangan Sumber Daya Manusia Terhadap Kinerja Pegawai PT. Indojaya Agrinusa. Jurnal Ilmiah Methonomi Vol.3 No.2.

Rillya A. Kelejan, Victor P.K. Lengkong dan Hendra N. Tawas. 2018. Pengaruh Perencanaan Sumber Daya Manusia Dan Pengalaman Kerja Terhadap Kinerja Karyawan Di PT. Air Manado. Jurnal EMBA Vol.6 No.4

Rusydi, Muhammad. 2017. Customer Excellence. Jakarta: Gosyen Publishing Dessler.

Sedarmayanti. 2016. Manajemen Sumber Daya Manusia, Reformasi Birokrasi dan Manajemen Pegawai Negeri Sipil. Bandung: Refika Aditama.

Sugiyono. 2015. Metode Penelitian Kuantitatif, Kualitatif, dan R\&D. Bandung: CV. Alfabeta. 
Vol. 1 No. 22020

Suhendi, Hendi. 2018. Perilaku Organisasi. Bandung: Pustaka Setia

Sutrisno, Edy. 2016. Manajemen Sumber Daya Manusia (Cetakan Ke Tujuh). Jakarta: Kencana Prenada Media Group.

Stoner, James. 2016.Manajemen (Edisi Terjemahan). Jakarta: Prenhalindo. 